\title{
Influence and Consequences of Depression in Cyberbullying Manifested In Adolescence
}

\author{
Patricia Martínez Lanz \\ Anáhuac University, México. \\ María Begoña Fernández Solana \\ Anáhuac University, México. \\ Mayra Karam Dagdug \\ Anáhuac University, México. \\ Ma. De Lourdes Valdés la Vallina \\ Anáhuac University, México.
}

\begin{abstract}
The use of mass media, especially social networks is part of a lifestyle in the world mainly in adolescents. The currently access to the network is seeing high: $80 \%$ of adolescents have Internet access, and $70 \%$ are online daily, so the information and dissemination has become difficult to reduce, as well as the need they have of remaining on the network. The aim of the study was to determine the relationship of the main variables involved in this phenomenon, including domestic violence, levels of depression, and self-esteem in adolescents between 12 and 16 years. The questionnaire applied to the participants consisted of 5 parts: 1) general information of the subject; 2) type of environment in which the subject lives; 3) self-esteem; 4) type of participation on cyberbullying, being victim or aggressor; 5) depression. The results showed that young people with high levels of violence have high levels of cyberbullying, as well high levels of depression. Subjects who had high self-esteem were observed with low levels of domestic violence and participants with low levels of depression showed a low level of cyberbullying. On the other hand, subjects with low levels of cyberbullying have adequate self-esteem as well as participants who reported lower levels of depression. Therefore depression is a factor that is directly related to the conduct of cyberbullying, as well as the style of home life that adolescents have today.
\end{abstract}

Key Words: Depression, Adolescence, Self Esteem, Violence, Cyberbullying, Social Network, Emotional State, Participation.

\section{INTRODUCTION}

The media involve the most races and are defined as a set of techniques and devices capable of transferring emotional or intellectual messages in a given time, many people and especially over long distances.

Social networks are virtual societies, i.e., they bring together people relate to each other and share information and common interests. Its main objective is to make contact with people, either to create certain links or make new friends. Today there are more than 200 social networks, with over 800 million users worldwide and are growing every day. Most people who use social networks are young but today the number of users has increased and every time 
there are people of all ages. 80 percent of social network users worldwide have between 12 and 30 years, with the frequency of use among adolescents aged 12 to 19 years very high.

Among the main virtual activities through which people can socialize, find first sending emails (90\%), instant messaging (75\%), view photos or videos (68\%) and accessing social networks (61\%). The most used social networks are: Facebook (39\%), YouTube (28\%), Twitter and Hi5 (20\% and 6\%) (AMIPCI, 2011). Cyberbullying has been defined by several authors. According to Smith (2000), cyberbullying is an aggressive act and intentional carried out repeatedly and constant over time way, by using electronic forms of contact from a group or an individual against a victim who does not you can easily defend themselves. On the other hand, Willard (2005) defines this type of harassment, such as sending and hangs up harmful or cruel text or images over the Internet or other digital media. Belsey (2005) for his part conceptualizes cyberbullying as some aggressive use of information and communications technology (Lucio, 2009). According to Felix et al. in an investigation of cyberbullying among adolescents, the results indicated that $100 \%, 74 \%$ of incidents relate to harassment through messages and $26 \%$ to images. In this same study in gender, the results showed that women were further victims of cyberbullying and men showed a profile of stalkers. Finally it was found that $41.9 \%$ of cases of cyberbullying were associated with disciplinary action taken from schools (Felix Soriano, Godoy and Sancho, 2010).

The report on the habits of Internet users in Mexico by the Mexican Internet Association in 2010 , an increase in the number of users who surf the Internet compared to previous years was found. By 2010 the figure was 34.9 million users, of which $49 \%$ were women and $51 \%$ men. The highest percentage of users in terms of age group was between 12 to 17 years (27\%), second place 18 to 24 years (23\%) and last third of 25 to 34 years (17\%) (Garaigordobil, 2011).

When a person has a depressive disorder, it will interfere with their daily life and normal functioning, causing pain both for those who have this disorder and those who care about him. Depression is a serious illness, and most people who have it need treatment. You can become a serious health problem, especially when it is long lasting and (moderate or severe) intensity, because in the worst cases can lead to suicide. The symptoms are:

- Persistent feelings of sadness, anxiety, or emptiness.

- Feelings of hopelessness and / or pessimism.

- Feelings of guilt, worthlessness and / or helplessness, irritability, restlessness.

- Loss of interest in activities or hobbies once pleasurable, including sex.

- Fatigue and lack of energy.

- Difficulty concentrating, remembering details and making decisions.

- Insomnia, waking up too early, or oversleeping.

- Overeating or loss of appetite.

- Suicidal thoughts or suicide attempts.

- Ongoing aches and pains, headaches, or digestive problems that do not ease even with treatment.

As for the etiology, there is no specific cause of depression, the result of the combination of genetic, biochemical and psychological factors. The most common problems found in Mexican adolescents today are directly related to the family environment in which are found. There is a conflicting relationship with parents, discussions about the present economic situation, low 
self-esteem and response of coping with stress in aggressive and impulsive way (Forteza et al., 2003).

Adolescence is one of the critical periods for the development of self-esteem; distinguished from others, know their limitations and possibilities, talent, skills, and recognition as person are aspects that are part of this process. During adolescence are physical, cognitive, social and emotional changes; develops the ability to think and reflect about oneself and others, as well as physical changes. Adolescents begin to question is mainly on issues of physical attractiveness, intelligence, and social acceptance. Gradually, they begin to separate belief that true about himself is what it considers wrong, developing concepts on his person. As greater is the acceptance that you feel, the chances of success will be greater.

Violence occurs when physical, verbal or psychological damage is caused to another person. Physical violence is when using any object, instrument or physical force to cause physical damage both external as internal, you can take the form of fight and is not accidental. Verbal violence refers to insults, threats, nicknames and harmful expressions. This is undoubtedly the most common and therefore the most repeated; psychological violence often goes unnoticed or is harder to notice and refers to psychological games, blackmail, disinterest, rejection and isolation. Violence can be also indirectly, i.e. when it is not directed to one person, but to animals or objects (Fernandez, 2000).

Domestic violence is exercised by a family member against another and action which produces a non-accidental damage on the physical or psychological aspect (Almenares, 1999). Domestic violence also can be exercised by the omission of duties and responsibilities, i.e. when a father leaves his son and does not provide him food and care suitable to this need (Almenares, 1999).

\section{SCALES}

Different scales were selected in order to make a global measuring instrument, taking into account different variables to investigate, namely:

a. Scales of victimization through mobile phone and over the Internet. It consists of 8 items with 4 ranges of response indicating the intensity of the victimization.

b. The scale of victimization over the Internet has the same range of response that the previous scale and the same 8 items, to which add 2 items more related to violation of privacy and the phishing attacks.

c. Current victimization through the mobile phone and the Internet. The intensity of the harassment is evaluated with a question exclusively for the use of the mobile phone and another for the duration of victimization through mobile phone and Internet, also the duration of the harassment is evaluated with a question for the mobile phone and another for Internet, both with 4 response options.

\section{Participants}

\section{MATERIAL AND METHOD}

The population is directed the study is high school students with a range of 12 to 16 years old respectively covering three different degrees of study: first high school third high school. The study tries to have a socio-cultural perspective, so that the instrument was applied in secondary public and private, as well as in both sexes.

\section{Instrument}

Instrument consists of five parts. 
i. General information. This category contains general data of the subject such as: sex, age and year currently enrolled. Likewise, there are three questions corresponding to the constellation family, taking into account: marital status of parents, problems considering the important subject (addictions, physical or verbal abuse, unemployment, infidelity) and finally, members who live at the House of the subject.

ii. Domestic Violence. Raised questions on the instrument to detect the type of environment in which it operates the subject, as well as also the type of communication that exists.

iii. Self-Esteem. This category has questions related to self-esteem, consists of 12 reagents, in order to determine how it perceives itself and how others perceive you.

iv. Cyberbullying. This category consists of 18 reagents, written directly in order to assess victimization, promoting cyberbullying, participation and behavior in social networks. Response options are raised in a negative way, i.e. to lower-value response (never), less likelihood or degree of cyberbullying. The four types of response are: never, sometimes, many times, and always.

v. Depression. The last part of the instrument consists of 20 reagents related to the recent emotional state of the subject. This evaluates the number of days that have been important or representative in the last week. Response options have a value of 1-4, the four being the most serious or negative. The responses are divided in: 0 days, 1 or 2 days, 3 or 4 days and 5 or more days.

\section{PROCEDURE}

The instrument was applied to students in first, second and third grades of 12 to 16 years of age, in two private schools, one of men and one of women. It was answered on an individual basis, in the classroom. A questionnaire consisting of four scales explained previously domestic violence, self-esteem, cyberbullying and depression, within their educational institutions, application was individually and stressing the confidentiality of the study.

\section{RESULTS}

The results indicate (table 1) to $52.7 \%$ of the population is male and $47.3 \%$ females. Divided into three categories of ages, where 33.3\% refers to adolescents aged between 12 and 13 years old, $59.2 \%$ between 14 and 15 years of age and 7.1\% to 16 year-olds. Schooling in which these subjects are belongs to first high school (34.7\%), second high school (34.4\%) and third high school (30.3\%).

Here is observed that $4.1 \%$ experienced problems related to addictions, $6.1 \%$ is related to physical and/or verbal aggression, $2.4 \%$ reported infidelity and jealousy, $11.2 \%$ lack of money/unemployment-related problems and $76.2 \%$ means there is no problem. $83 \%$ of teens report that their parents are married, while $15.7 \%$ are separated/divorced and only $1.4 \%$ lost to your spouse. And, $91.8 \%$ live with their parents, $3.4 \%$ with a family member and $4.8 \%$ with other people.

The results showed a relationship between levels of cyberbullying and levels of domestic violence, in which young people with high levels of violence also had high levels of cyberbullying. The highest percentage of participants with low levels of domestic violence (90.9\%) reported low levels of cyberbullying (Figure 1).

In Figure 2, the relationship between depression levels and levels of domestic violence is shown. Cases with severe levels of violence had high levels of depression. $92.8 \%$ of participants with low levels of domestic violence reported lower levels of depression. At the same time, in 
Figure 3 it can be seen that the identified relationship between self-esteem and domestic violence, severe level associated violence with a low level of self-esteem. 94\% of participants had high levels of self-esteem, relative to a low level of domestic violence.

Table 1. Population features.

\begin{tabular}{|c|c|c|}
\hline Variables & Indicator & Population \\
\hline \multirow{2}{*}{ Sex } & Female & $47.3 \%$ \\
\hline & Male & $52.7 \%$ \\
\hline \multirow{5}{*}{ Age } & 12 years old & $5.1 \%$ \\
\hline & 13 years old & $28.2 \%$ \\
\hline & 14 years old & $32.0 \%$ \\
\hline & 15 years old & $27.2 \%$ \\
\hline & 16 years old & $7.1 \%$ \\
\hline \multirow{3}{*}{ Scholarship } & First grade (Secondary) & $34.7 \%$ \\
\hline & Second grade (Secondary) & $34.4 \%$ \\
\hline & Third grade (Secondary) & $30.3 \%$ \\
\hline \multirow{7}{*}{ Problem at home } & Adictions & $4.1 \%$ \\
\hline & Physical agression & $1.0 \%$ \\
\hline & Verbal agression & $5.1 \%$ \\
\hline & Infidelidad/celos & $2.4 \%$ \\
\hline & Unemployeed/lack of money & $11.2 \%$ \\
\hline & Other & $5.1 \%$ \\
\hline & No problem & $71.1 \%$ \\
\hline \multirow{4}{*}{ Parents } & Married & $83 \%$ \\
\hline & Separated & $3.1 \%$ \\
\hline & Divorced & $12.6 \%$ \\
\hline & Widower & $1.4 \%$ \\
\hline \multirow{3}{*}{ Living place } & Parents & $91.8 \%$ \\
\hline & Some relative & $3.4 \%$ \\
\hline & Others & $4.8 \%$ \\
\hline
\end{tabular}




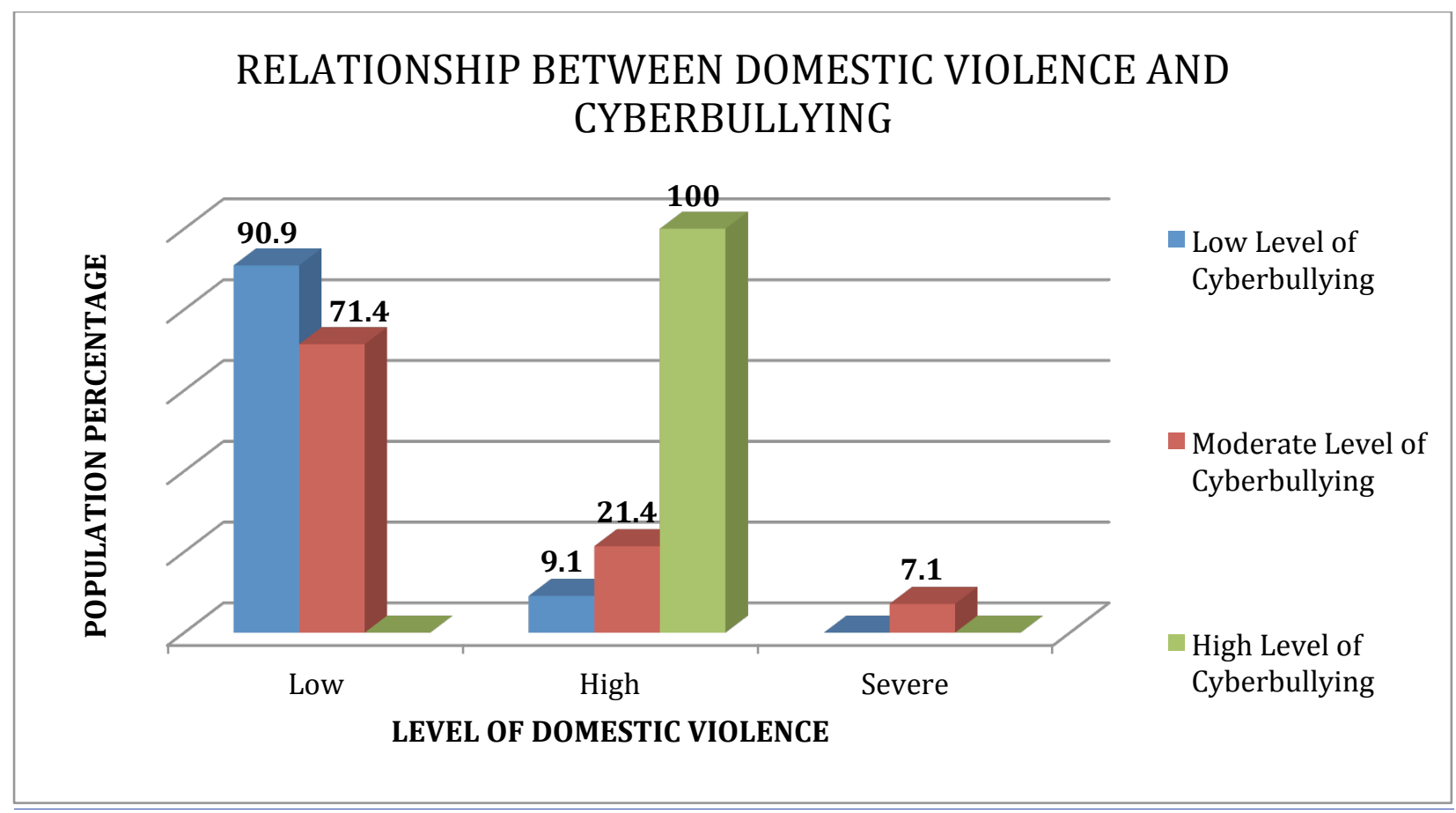

Figure 1. Relationship between cyberbullying and domestic violence

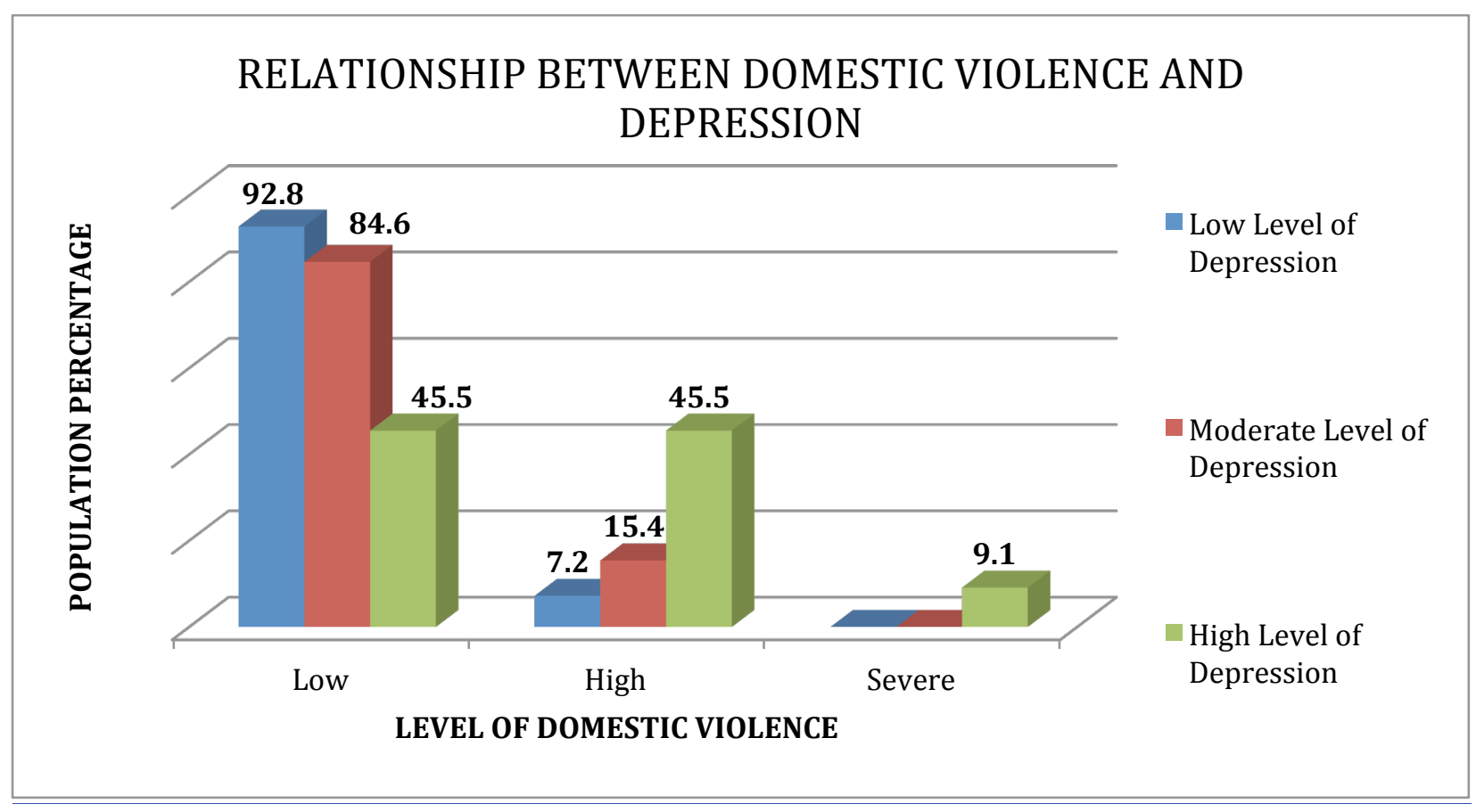

Figure 2. Relationship between depression and domestic violence 


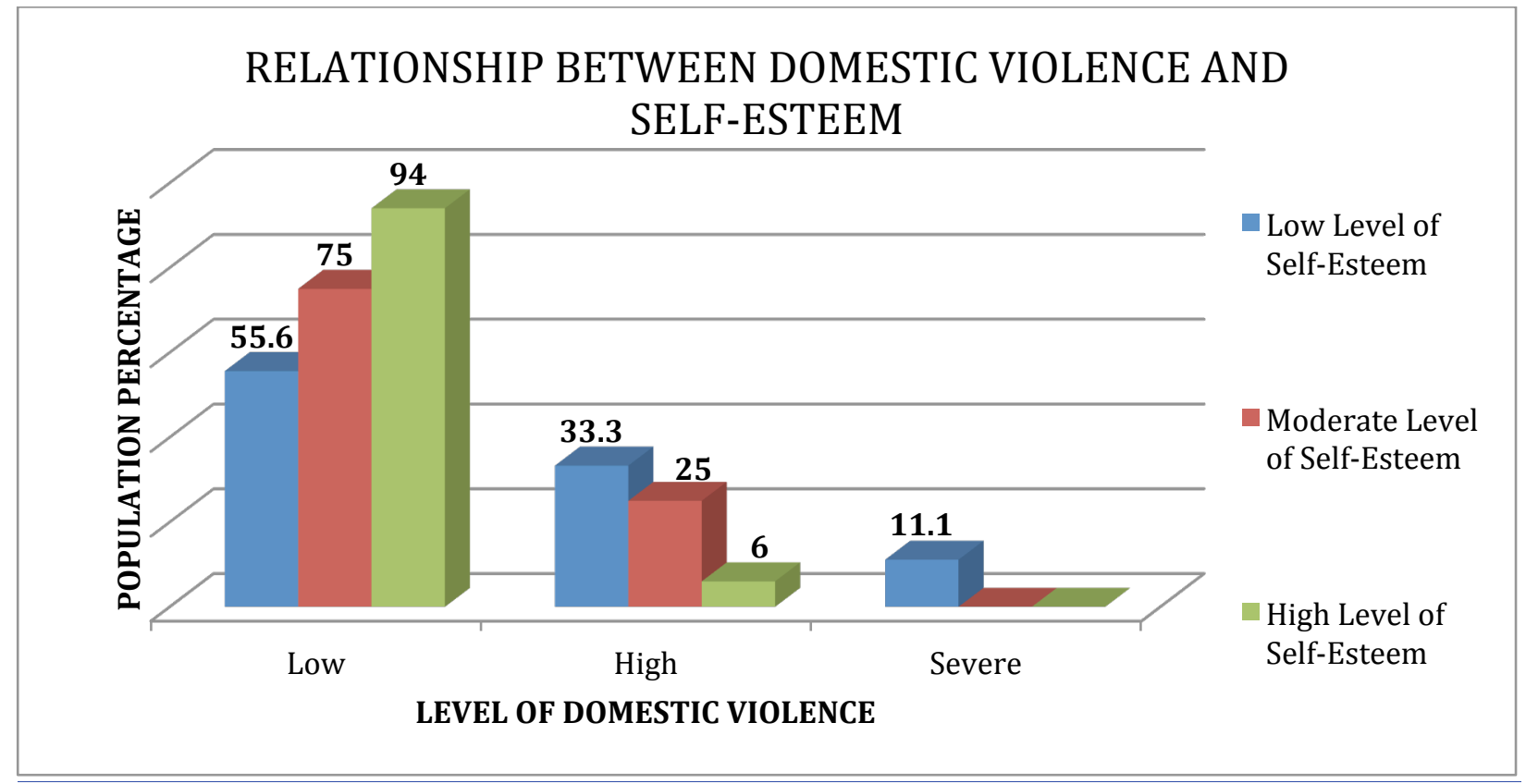

Figure 3. Relationship between self-esteem and violence.

The relationship between depression and cyberbullying shown in Figure 4 identifies high levels of depression also high levels of cyberbullying. In particular, a high percentage of the sample (98.7\%) expressed low levels of depression and a low level of involvement in cyberbullying

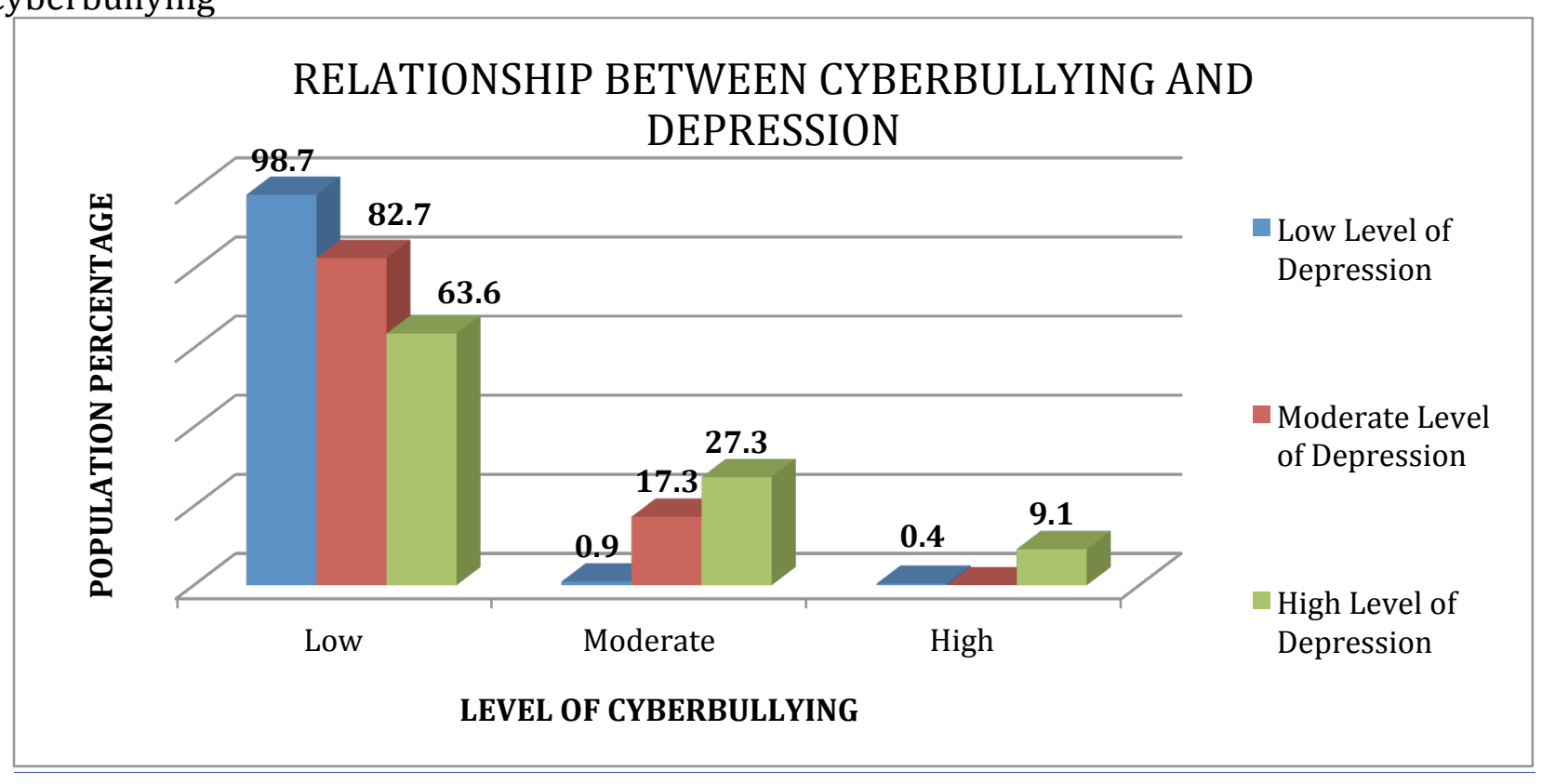

Figure 4. Relationship between cyberbullying and depression.

Similarly, Figure 5, the level of low self-esteem is related to a higher level of cyberbullying; besides that $97.9 \%$ of participants they had low levels of cyberbullying associated with high levels of self-esteem 


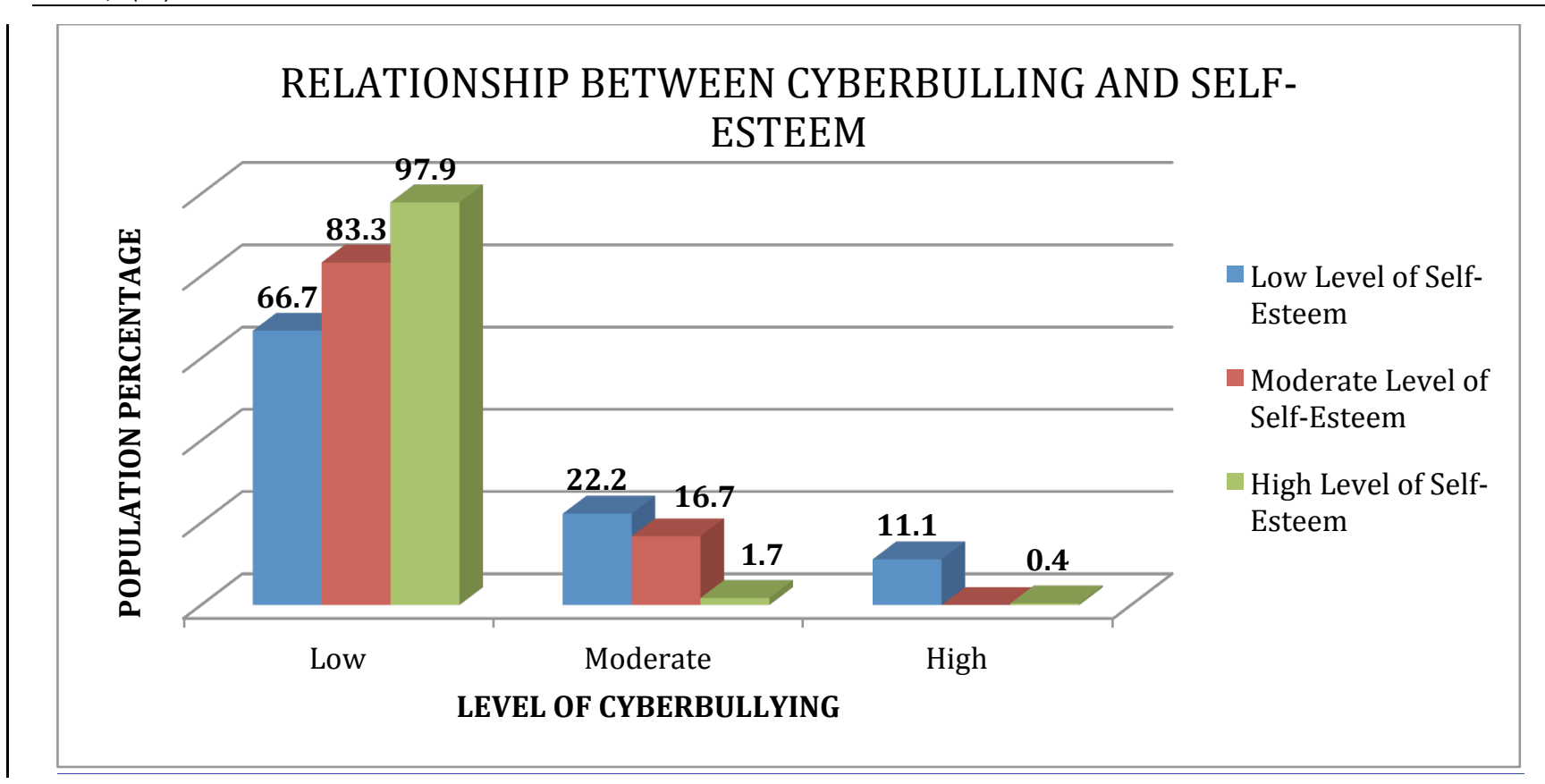

Figure 5. Relationship between cyberbullying and self-esteem.

Finally, Figure 6 shows the results for the analysis of the relationship between self-esteem and depression level, finding that $85.5 \%$ of subjects were identified with conditions of low levels of depression relative included at a high level self-esteem, being able to establish that overall, a low level of self-esteem is associated with a higher level of depression.

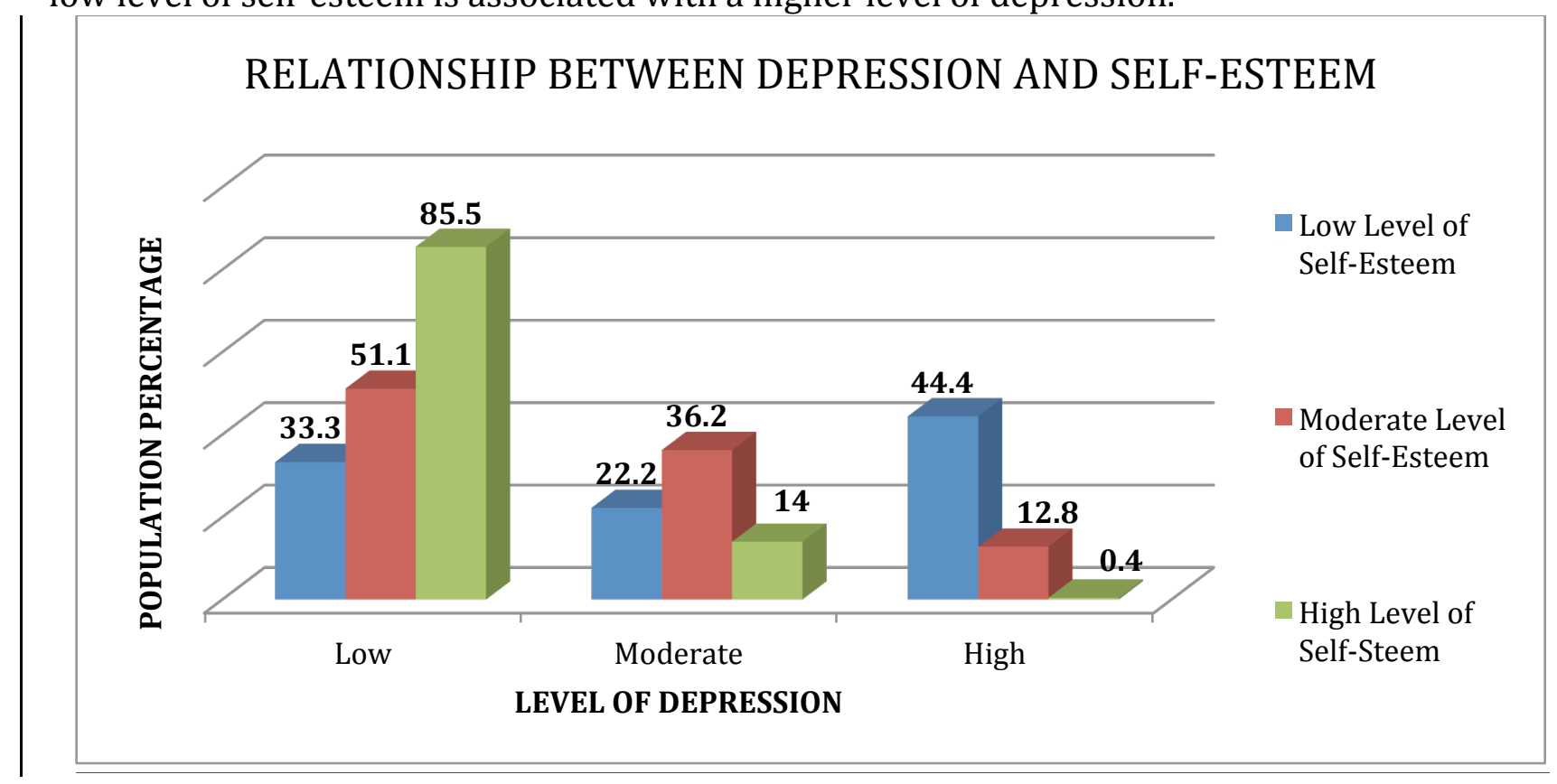

Figure 6. Relationship between depression and self-esteem.

DISCUSSION AND CONCLUSIONS

In the present study the relationship between depression, self-esteem, cyberbullying and domestic violence was discussed, in adolescents aged 12 to 16 years. The results showed significant differences, where mainly the relationship shown that variables have to each other and how they affect the phenomenon of cyberbullying.

Each of the variables was classified in three levels (low, moderate and high), except in the case of domestic violence, which was divided into: low, high and severe. Regarding differences by 
sex, age and education, no statistically significant differences were, unlike the relationship with housing and marital status of the parents.

Infidelity related problems and addictions are reflected in a high percentage of depression and low self-esteem. On the other hand, it found that the behaviors of physical and / or verbal aggression and unemployment problems are related to high levels of both cyberbullying and domestic violence.

Based on the marital status of the parents, it was observed that when parents are separated, adolescents have higher levels of violence and low self-esteem; whereas in the case of married or widowed parents, there is a high level of cyberbullying. In contrast, when subjects living with others (not specified) there is a link with severe violence and a higher level of depression.

After analyzing the behaviors observed among the different variables, it was found that a high level of cyberbullying is related to: high depression, low self-esteem and severe violence.

It is also shown that a high level of depression is associated with severe violence and low selfesteem; and that, in turn, these two (severe violence and low self-esteem) are interrelated in the same way.

Consequently, the initial proposals, where a significant relationship between the variables involved are checked expected.

\section{Referencies}

Almenares. M, (1999). Comportamiento de la violencia intrafamiliar. Revista cubana de Medicina General Integral, V.15, N.3. Recuperado de internet noviembre 2014: http://scielo.sld.cu/scielo.php?script=sci_arttext\&pid=S086421251999000300011

Asociación Mexicana de Internet (2011). Hábitos de los usuarios de Internet en México 2010. Recuperado desde: http://www.amipci.org.mx/noticias/index/cvenoticia/1021.

Lucio, L. A. (2009). Agresores escolares en el ciberespacio; el cyberbullying en preparatorias mexicanas. Asamblea General ALAFEC. Recuperado de Internet 2014: http://convivenciaescolar.net/wp/wpcontent/uploads/2009/10/ARTICULO_ECUADOR.pdf

Félix, V; Soriano, M; Godoy, C y Sancho, S. (2010). El ciberacoso en la enseñanza obligatoria. Aula Abierta 2010, Vol. 38, núm. 1, Recuperado de Internet 2014:

http://scholar.es/scholar?q=diferencia+de+genero+en+ciberacoso\&btnG=\&hl=es\&as_sdt=0\%2C5

Fernández, I. (2000). Prevención de la violencia y resolución de conflictos. Nancea S. A. Madrid.

Garaigordobil, M. (2011). Prevalencia y consecuencias del cyberbullying: una revisión. Octubre 12, 2014, de International Journal of Psychology and Psychological Therapy Sitio web:

http://www.ijpsy.com/volumen11/num2/295/prevalencia-y-consecuencias-del-cyberbullying-es.pdf

Forteza, C, Ramos. L, Gutiérrez. M. y Echeagarray. F. (2003). Correlatos psicosociales de depresión, ideación e intento suicida en adolescentes mexicanos. 20 de octubre del 2014, de Instituto Nacional de Psiquiatría «Ramón de la Fuente Muñiz» y Center for Health Disparities Solutions Recuperado desde:

http://www.unioviedo.net/reunido/index.php/PST/article/download/8053/7917\&sa 